\title{
Optimization of Synthesis of Seleno-Sargassum fusiforme (Harv.) Setch. Polysaccharide by Response Surface Methodology, Its Characterization, and Antioxidant Activity
}

\author{
Yu-Bin Ji, ${ }^{1,2}$ Fang Dong, ${ }^{1,2}$ Miao Yu, ${ }^{1,2}$ Long Qin, ${ }^{1}$ and Dan Liu ${ }^{1}$ \\ ${ }^{1}$ Research Center on Life Sciences and Environmental Sciences, Harbin University of Commerce, Harbin 150076, China \\ ${ }^{2}$ Engineering Research Center of Natural Anticancer Drugs, Ministry of Education, Harbin 150076, China \\ Correspondence should be addressed to Yu-Bin Ji; jyb@hrbcu.edu.cn
}

Received 29 May 2013; Accepted 1 September 2013

Academic Editor: Alexander Govaris

Copyright (C) 2013 Yu-Bin Ji et al. This is an open access article distributed under the Creative Commons Attribution License, which permits unrestricted use, distribution, and reproduction in any medium, provided the original work is properly cited.

\begin{abstract}
The response surface methodology was employed to optimize the synthesis conditions of seleno-Sargassum fusiforme (Harv.) Setch. polysaccharide. Three independent variables (reaction time, reaction temperature, and ratio of $\mathrm{Na}_{2} \mathrm{SeO}_{3}$ to SFPSI) were tested. Furthermore, the characterization and antioxidant activity of Se-SFPSI in vivo were investigated. The result showed that the actual experimental Se content of Se-SFPSI was $3.352 \mathrm{mg} / \mathrm{g}$ at the optimum reaction conditions of reaction time $8 \mathrm{~h}$, reaction temperature $71^{\circ} \mathrm{C}$, and ratio of $\mathrm{Na}_{2} \mathrm{SeO}_{3}$ to SFPSIB $1.0 \mathrm{~g} / \mathrm{g}$. A series of experiments showed that the characterization of Se-SFPSIB was significantly different from that of SFPSIB. Additionally, antioxidant activity assay indicated that the Se-SFPSIB could increase catalase (CAT), superoxide dismutase (SOD), and glutathione peroxidase (GSH-Px) activity of mice bearing tumor $\mathrm{S}_{180}$ in blood, heart, and liver while decreasing malondialdehyde (MDA) levels. It can be concluded that selenylation is a feasible approach to obtain selenopolysaccharide which was utilized as highly biological medicine or functional food.
\end{abstract}

\section{Introduction}

Sargassum fusiforme (Harv.) Setch., which is cultivated in the sea of China and eastern Asia, is a traditional edible and medicinal plant. It is used for treating some diseases, such as diabetes, high cholesterol, and thyroid disease [1]. Moreover, research shows that Sargassum fusiforme (Harv.) Setch. polysaccharide (SFPS) as an active ingredient [2] has biological activity in vivo [3] and in vitro [4].

Meanwhile, selenium is a necessary micronutrient for human beings and animals [5], but it is usually poisonous in inorganics [6]. As an organic selenium compound, selenopolysaccharide maintains the basic configuration of the polysaccharide and physiological functions of selenium. Moreover, seleno-polysaccharide can improve selenium bioavailability and reduce the toxicity [7] and side effects of inorganic selenium [8].

Due to the insufficiency of natural seleno-polysaccharide in nature, artificial method is the best way to increase the yield of seleno-polysaccharide. Compared with biotransformation, chemical synthesis is the most effective approach to harvest seleno-polysaccharide. It is also well known that the structure of polysaccharide is intimately related to its functions. The microstructure of seleno-polysaccharide may be changed by chemical modification.

Up to now, little information is available on the optimal conditions for seleno-seleno-Sargassum fusiforme (Harv.) Setch. polysaccharide (Se-SFPS) synthesis. Meanwhile, no experiments were employed to explore its characterization and antioxidant activity. Therefore, this paper optimized synthesis of seleno-Sargassum fusiforme (Harv.) Setch. polysaccharide by response surface methodology (RSM) $[9,10]$ and investigated its characterization and antioxidant activity.

\section{Experimental}

2.1. Purification and Isolation of SFPS. The crude SFPS was extracted from the dried body of Sargassum fusiforme (Harv.) Setch. which was purchased from Wenzhou City, China. 
Protein of crude polysaccharide solution was discarded by $0.1 \%(\mathrm{~g} / \mathrm{v})$ papain and Sevag, and pigment was treated with $\mathrm{H}_{2} \mathrm{O}_{2}$. Then, SFPSI was obtained from SFPS solution that was precipitated by dehydrated alcohol to a final concentration of $20 \%$ (v/v). After that, SFPSI was isolated by DEAE-52 column chromatogram with different $\mathrm{NaCl}$ solutions $(0.0,0.05,0.1$, $0.2,0.3,0.5$, and $0.8 \mathrm{~mol} / \mathrm{L})$, respectively. The component eluted by $0.05 \mathrm{~mol} / \mathrm{L} \mathrm{NaCl}$ had the maximum proportion, named SFPSIB. SFPSI was used to optimize the synthesis, and Se-SFPSIB was used to detect the characterization and antioxidant activity.

2.2. Selenylation. Different ratios of $\mathrm{Na}_{2} \mathrm{SeO}_{3}$ and SFPSI were dissolved by $\mathrm{HNO}_{3}(100 \mathrm{~mL}, 0.05 \%)$ in Erlenmeyer flasks. Then, the mixed solution was reacted in the designed reaction time, reaction temperature, and water bath shaking rate. After the reaction, $\mathrm{Na}_{2} \mathrm{CO}_{3}$ was added to the reacted solution to adjust $\mathrm{pH}$ to 5-6. The solution was centrifuged to remove the insoluble residue $\left(3000 \times \mathrm{g}\right.$ for $5 \mathrm{~min}$, at $\left.20^{\circ} \mathrm{C}\right)$ and then dialyzed with dialysis membrane (Molecular Weight Cutoff: $8000 \sim 14000$, Solarbio Science \& Technology Co., Ltd., Beijing, China) in running water. Ascorbic acid was used to detect whether free $\mathrm{SeO}_{3}{ }^{2-}$ was dialyzed out from the solution. When ascorbic acid did not redden the solution, the Se-SFPSI solution was collected and freeze-dried [10].

2.3. Optimization of Synthesis of Se-SFPSI. According to the results of monofactor experiments for Se-SFPSI, a RSM was used to optimize the reaction conditions for Se-SFPSI. A multivariate study based on Box-Behnken design (BBD) was chosen to evaluate effects of reaction parameters. Three independent variables in a $\mathrm{BBD}\left(X_{1}\right.$, reaction time; $X_{2}$, reaction temperature; $X_{3}$, ratio of $\mathrm{Na}_{2} \mathrm{SeO}_{3}$ to SFPSI) at three levels were performed. Table 1 showed the range of independent variables and their levels. Se content as response value was calculated according to the linear equation $(y=0.0197 x+$ $\left.0.0343, R^{2}=0.9998\right)$, which was detected by toluene-1,2phenylenediamine method and measured at $334 \mathrm{~nm}$ by 752 type UV-Vis spectrophotometer (Shanghai Spectrum Instruments Co., Ltd., Shanghai, China).

\subsection{Characterization Detection of Se-SFPSIB}

2.4.1. Detection of Particle Size and Zeta Potential. The solution of Se-SFPSIB and SFPSIB in water $(0.2 \mathrm{mg} / \mathrm{mL})$ was detected by Zetasizer Nano ZS90 nanoparticle size and zeta potential analyzer (British Malvern Instruments Co., Ltd., Worcestershire, UK). All data was analyzed by software of particle size distribution and zeta potential.

2.4.2. Determination of Differential Scanning Calorimetry. Se-SFPSIB and SFPSIB were detected by Pyris Diamond differential scanning calorimetry (Perkin Elmer Co., Ltd., Waltham, USA) (gas: nitrogen $50.0 \mathrm{~mL} / \mathrm{min}$, heating rate: $10^{\circ} \mathrm{C} / \mathrm{min}$, and scope of temperature: $20 \sim 230^{\circ} \mathrm{C}$ ).

2.4.3. X-Ray Diffraction. Se-SFPSIB and SFPSIB were detected by PW1700 X-ray diffraction instrument (Philips
TABLE 1: Coding schedule of response surface methodology.

\begin{tabular}{lccc}
\hline Independent variables & \multicolumn{3}{c}{ Factor level } \\
& -1 & 0 & 1 \\
\hline$X_{1}$ reaction time $(\mathrm{h})$ & 7 & 8 & 9 \\
$X_{2}$ reaction temperature $\left({ }^{\circ} \mathrm{C}\right)$ & 60 & 70 & 80 \\
$X_{3}$ ratio of $\mathrm{Na}_{2} \mathrm{SeO}_{3}$ to $\mathrm{SFPSI}(\mathrm{g} / \mathrm{g})$ & 0.6 & 0.8 & 1.0 \\
\hline
\end{tabular}

Electronics Ltd., Amsterdam, Netherlands) (radiation: $\mathrm{Cu} \mathrm{K} \alpha, \lambda=1.5418 \AA, 2 \theta=10^{\circ} \sim 80^{\circ}$ ).

2.4.4. Observation under Scanning Electron Microscopy. The dried powder of Se-SFPSIB and SFPSIB fixed on the conductive adhesive was coated by Au. The three-dimensional images were observed by QUANTA 200-scanning electron microscope (FEI Co., Ltd., Hillsboro, US).

2.5. Antioxidant Activity Assay In Vivo. Kunming mice, 30 days old, were transplanted tumor $\mathrm{S}_{180} 0.2 \mathrm{~mL}$ (living cells number $\geq 97 \%$ ) in the armpit. The weighed mice after inoculation were randomly divided into six groups $(n=8)$, half male and half female: (1) negative group: mice were treated with normal saline; (2) positive group: mice were treated with lentinan at a dosage of $100 \mathrm{mg} /(\mathrm{kg} \cdot \mathrm{d})$; (3) SFPSIB group: mice were treated with SFPSIB at a dosage of $100 \mathrm{mg} /(\mathrm{kg} \cdot \mathrm{d})$; (4) Se-SFPSIB groups: mice of low-, medium-, and high-dose groups were treated with Se-SFPSIB at the dosage of 50,100 , and $150 \mathrm{mg} /(\mathrm{kg} \cdot \mathrm{d})$, respectively.

After $24 \mathrm{~h}$ of inoculation, the mice bearing tumor $\mathrm{S}_{180}$ were treated in peritoneal injection (i.p.) for 10 days. Then, CAT, MDA, SOD, and GSH-Px of mice bearing tumor $\mathrm{S}_{180}$ in blood, heart, and liver were detected by antioxidant assay kits, obtained from Nanjing Jiancheng Bioengineering Institute, China.

2.6. Statistical Analysis. The experimental data was analyzed by SPSS 16.0 software (SPSS Inc., Chicago, USA). Statistical comparison within groups was carried out by one-way ANOVA.

\section{Results and Discussion}

3.1. Single Factor Assays. Figure 1 showed the effects of single factors on Se content in Se-SFPSI. As shown in Figure 1(a), Se content in Se-SFPSI reached a maximum value at $8 \mathrm{~h}$, and Se content decreased after $8 \mathrm{~h}$. Figure 1(b) showed that Se content in Se-SFPSI reached a maximum value at $70^{\circ} \mathrm{C}$, and Se content decreased when the reaction temperature was $80^{\circ} \mathrm{C}$. The reason for these results was that more and more monosaccharide and oligosaccharide were hydrolyzed from SFPSI by acidic water for the longer time and at the higher temperature. When the reacted solution was dialyzed with dialysis membrane in running water, the lower molecular weight monosaccharide and oligosaccharide were dialyzed out from solution. Se was introduced into monosaccharide, and oligosaccharide also was removed from dialysis membrane. Herein, $6-8 \mathrm{~h}$ and $60-80^{\circ} \mathrm{C}$ were considered to be optimal reaction time and reaction temperature in the RSM. 


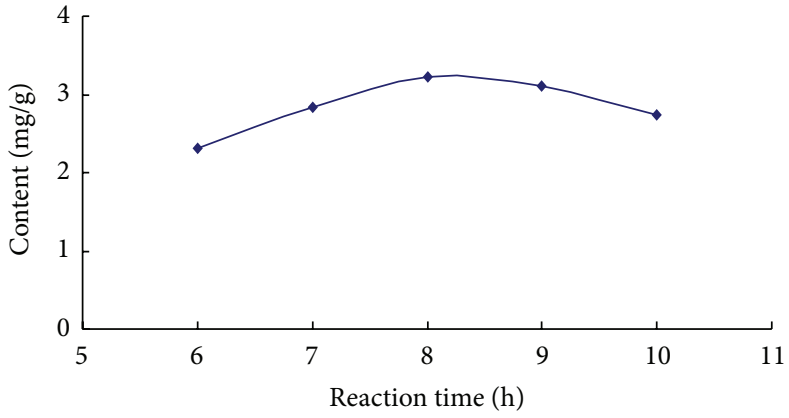

(a)

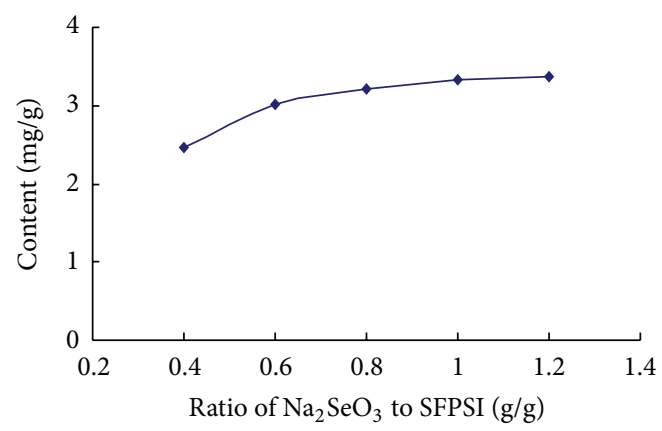

(c)

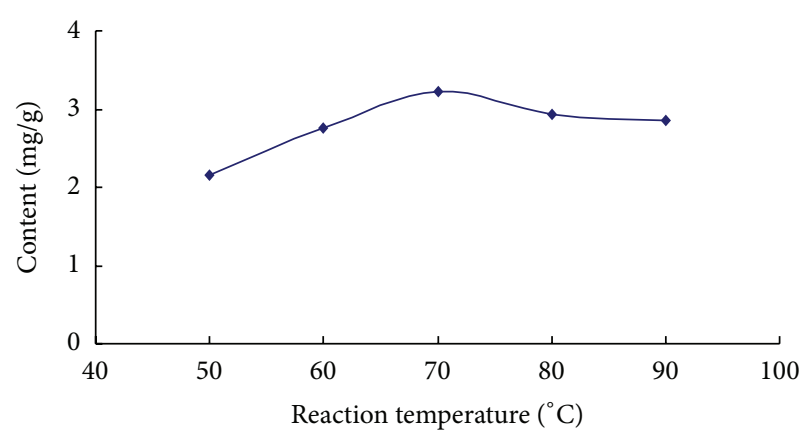

(b)

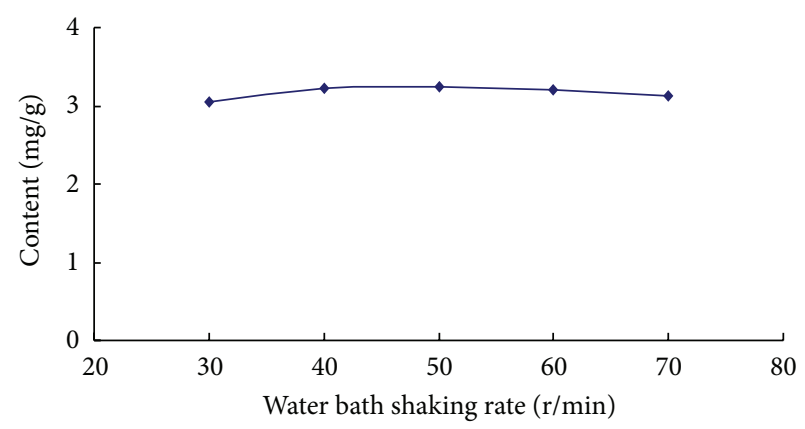

(d)

FIGURE 1: Effect of reaction time, temperature, ratio of $\mathrm{Na}_{2} \mathrm{SeO}_{3}$ to SFPSI, and water bath shaking rate on Se content. (a) Reaction temperature $70^{\circ} \mathrm{C}$, ratio of $\mathrm{Na}_{2} \mathrm{SeO}_{3}$ to SFPSI $0.8 \mathrm{~g} / \mathrm{g}$, and water bath shaking rate $40 \mathrm{r} / \mathrm{min}$; (b) reaction time $8 \mathrm{~h}$, ratio of $\mathrm{Na}_{2} \mathrm{SeO}_{3}$ to $\mathrm{SFPSI} 0.8 \mathrm{~g} / \mathrm{g}$, and water bath shaking rate $40 \mathrm{r} / \mathrm{min}$; (c) reaction time $8 \mathrm{~h}$, reaction temperature $70^{\circ} \mathrm{C}$, and water bath shaking rate $40 \mathrm{r} / \mathrm{min}$; $(\mathrm{d})$ reaction time $8 \mathrm{~h}$, reaction temperature $70^{\circ} \mathrm{C}$, and ratio of $\mathrm{Na}_{2} \mathrm{SeO}_{3}$ to SFPSI $0.8 \mathrm{~g} / \mathrm{g}$.

Figure 1(c) indicated that Se content in Se-SFPSI significantly increased at the ratio of $\mathrm{Na}_{2} \mathrm{SeO}_{3}$ to SFPSI $0.8 \mathrm{~g} / \mathrm{g}$, and then the curve kept a mild slope. Therefore, the ratio of $\mathrm{Na}_{2} \mathrm{SeO}_{3}$ to SFPSI range of $0.6-1.0 \mathrm{~g} / \mathrm{g}$ was adopted for the reaction. Figure 1(d) showed that Se content in Se-SFPSI obviously increased with the increase of water bath shaking rate, but there was no significant increase after $40 \mathrm{r} / \mathrm{min}$. This meant that $40 \mathrm{r} / \mathrm{min}$ was sufficient for the reaction. So, $40 \mathrm{r} / \mathrm{min}$ was determined as the reaction water bath shaking rate in next optimization experiments.

3.2. Experimental Results of Optimization by RSM. The results of RSM analysis of the variation of Se content in SeSFPSI with reaction time $\left(X_{1}\right)$, reaction temperature $\left(X_{2}\right)$, and ratio of $\mathrm{Na}_{2} \mathrm{SeO}_{3}$ to SFPSI $\left(X_{3}\right)$ are shown in Table 2. As shown in Table 2, Se content in Se-SFPSI ranged from 2.117 to $3.259 \mathrm{mg} / \mathrm{g}$.

By applying multiple regression analysis to the experimental data, the relationship between response variables and the test variables was obtained from the following secondorder polynomial equation:

$$
\begin{aligned}
Y= & 3.22+0.12 X_{1}+0.19 X_{2}+0.098 X_{3}-0.15 X_{1} X_{2} \\
& -0.051 X_{1} X_{3}-0.095 X_{2} X_{3}-0.28 X_{1}{ }^{2} \\
& -0.37 X_{2}{ }^{2}-0.043 X_{3}{ }^{2} .
\end{aligned}
$$

3.3. Model Fitting and Statistical Significance Analysis. As shown in Table 3, Se content in Se-SFPSI was significantly affected by linear parameters $\left(X_{1}, X_{2}, X_{3}\right)$, quadratic parameters $\left(X_{1}^{2}, X_{2}^{2}\right)$, and the interactive parameters $\left(X_{1} X_{2}, X_{2} X_{3}\right)$ $(P<0.05)$. However, the interactive parameter $\left(X_{1} X_{3}\right)$ and quadratic parameters $\left(X_{3}{ }^{2}\right)$ were not significant $(P>$ 0.05). Meanwhile, ANOVA of quadratic regression model demonstrated that the variables were adequately fitted to the regression equation $(P<0.01)$ and adequate with satisfactory determination coefficients $\left(R^{2}=0.9906\right.$, Adjusted $R^{2}=$ 0.9785). This meant that the model could be used to analyze and predict selenylation process results. In addition, a low value 0.0162 of coefficient of the variation (C.V.) illustrated a high degree of precision and a good deal of reliability of the experimental values.

3.4. Optimization of Selenylation Conditions. Figure 2(a) showed the interaction between reaction time and reaction temperature on the Se content in Se-SFPSI $(P=0.0003<$ $0.05)$. When the reaction time and reaction temperature increased, the Se content increased before the medium level and then decreased. As shown in Figure 2(b), when the reaction time ranged from $7 \mathrm{~h}$ to $9 \mathrm{~h}$ and the ratio of $\mathrm{Na}_{2} \mathrm{SeO}_{3}$ to SFPSI varied between $0.6 \mathrm{~g} / \mathrm{g}$ and $0.8 \mathrm{~g} / \mathrm{g}$, the Se content in Se-SFPSI increased gradually. However, the interactive effect between reaction time and the ratio of $\mathrm{Na}_{2} \mathrm{SeO}_{3}$ to SFPSI was not significant $(P=0.0659>0.05)$. As shown in Figure 2(c) 


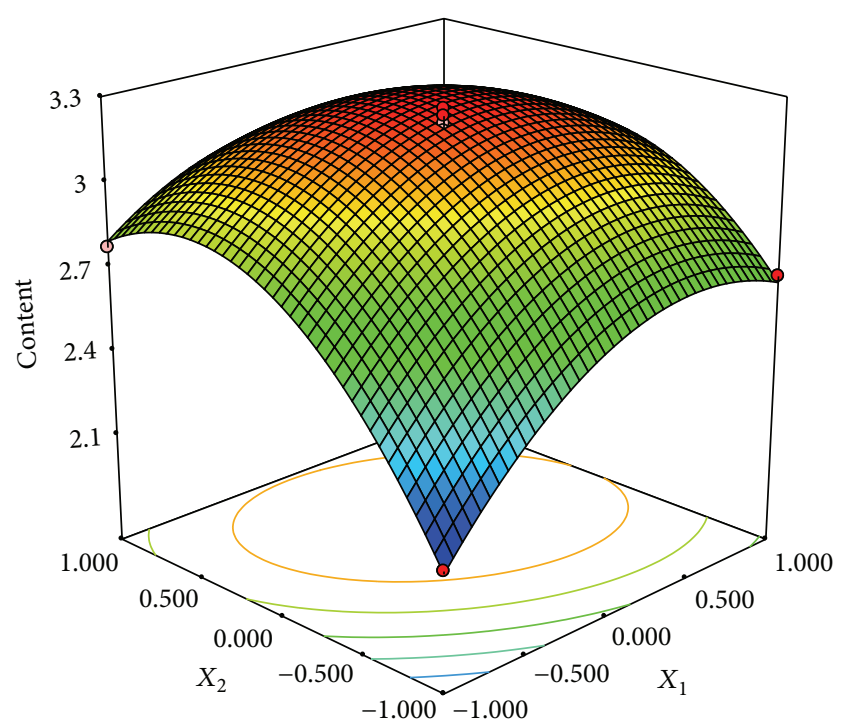

(a)

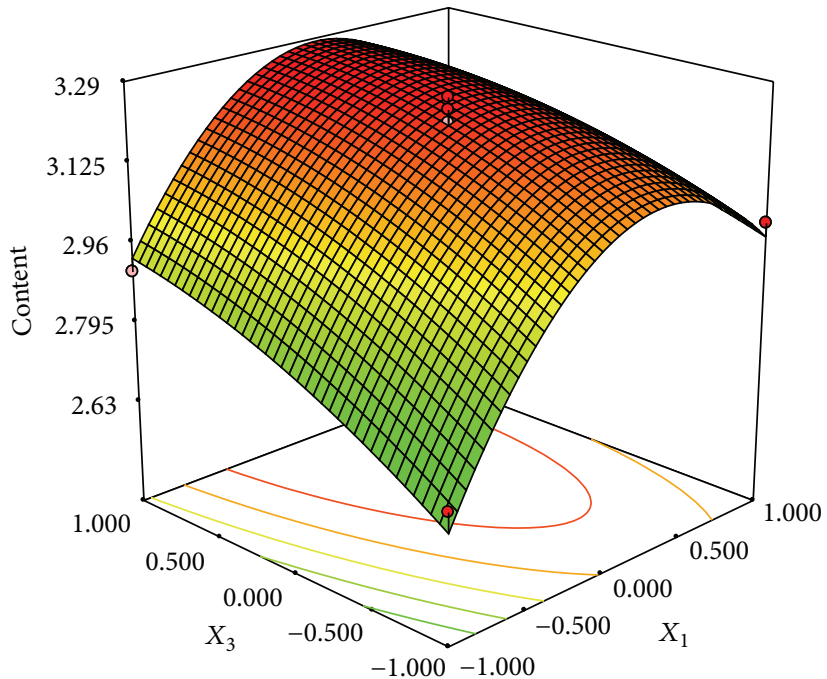

(b)

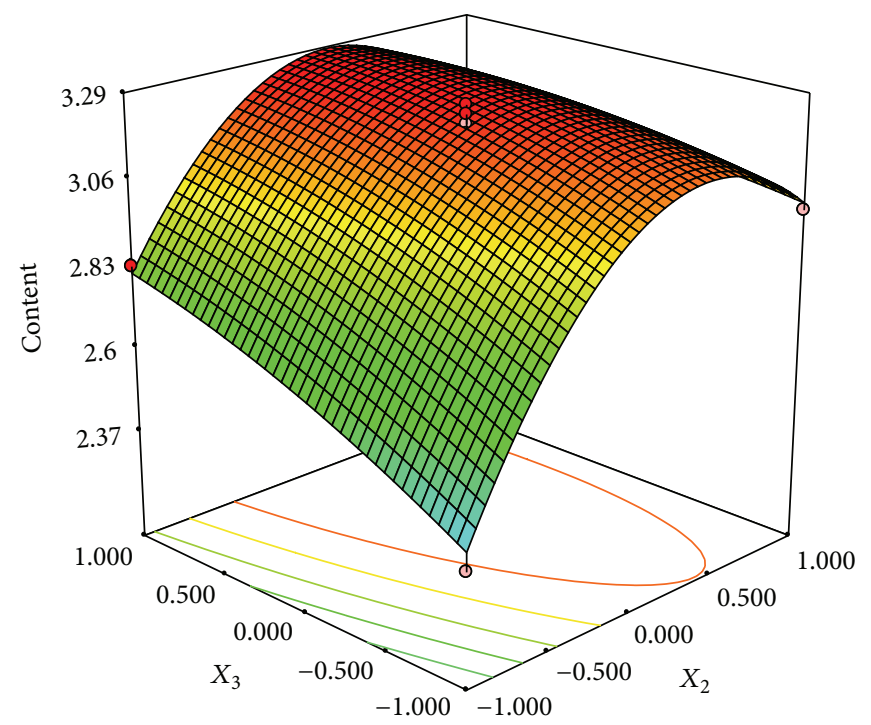

(c)

FIgURE 2: Response surface plots (3D) of reaction time, reaction temperature, and ratio of $\mathrm{Na}_{2} \mathrm{SeO}_{3}$ to SFPSI $\left(X_{1}\right.$ : reaction time; $X_{2}$ : reaction temperature; $X_{3}$ : ratio of $\mathrm{Na}_{2} \mathrm{SeO}_{3}$ to SFPSI).

and Table 3 , the interaction of reaction temperature and ratio of $\mathrm{Na}_{2} \mathrm{SeO}_{3}$ to SFPSIB had a much higher effect on the selenylation $(P=0.0048<0.01)$.

According to the results of the analysis of regression model, the optimal reaction conditions for Se-SFPSI were at reaction time of $8.09 \mathrm{~h}$, reaction temperature of $71.13^{\circ} \mathrm{C}$, ratio of $\mathrm{Na}_{2} \mathrm{SeO}_{3}$ to SFPSI of $1.0 \mathrm{~g} / \mathrm{g}$, and the predicted Se content in Se-SFPSI was $3.288 \mathrm{mg} / \mathrm{g}$.

3.5. Verification Experiment. For the actual operating convenience, the verification experiment was carried out under the optimum conditions: reaction time $8 \mathrm{~h}$, reaction temperature $71^{\circ} \mathrm{C}$, and ratio of $\mathrm{Na}_{2} \mathrm{SeO}_{3}$ to SFPSI $1.0 \mathrm{~g} / \mathrm{g}$. The experimental value was $(3.352 \pm 0.04) \mathrm{mg} / \mathrm{g}$, an average of triplicate experiments. The result confirmed the validity of the model, and the actual value was close to the predicted value.

\subsection{Characterization of Se-SFPSI}

3.6.1. Particle Size and Zeta Potential Distribution of SeSFPSIB. As shown in Figure 3, the particle size of Se-SFPSIB $(95.07 \mathrm{~nm})$ was significantly smaller than that of SFPSIB $(177.40 \mathrm{~nm})$. The reason was that SFPSIB was hydrolyzed into many smaller pieces by acidic water in selenylation. Figure 4 showed that the zeta potential of SFPSIB $(0.489 \mathrm{mV})$ was higher than that of Se-SFPSIB $(-0.194 \mathrm{mV})$. This meant that Se-SFPSIB was prone to clump and agglomerate. This also implied that stability of Se-SFPSIB was lower than that of SFPSIB in solution.

3.6.2. Differential Scanning Calorimetry Analysis. Figure 5 showed that the DSC spectrum shapes of Se-SFPSIB and SFPSIB were similar, and the major peaks of them were 
TABLE 2: Box-Behnken design of three variables and the experimental results.

\begin{tabular}{lcccc}
\hline No. & $X_{1} /$ reaction time $(\mathrm{h})$ & $X_{2} /$ reaction temperature $\left({ }^{\circ} \mathrm{C}\right)$ & $X_{3} /$ ratio of $\mathrm{Na}_{2} \mathrm{SeO}_{3}$ to SFPSI $(\mathrm{g} / \mathrm{g})$ & Se content in Se-SFPSI $(\mathrm{mg} / \mathrm{g})$ \\
\hline 1 & $-1(7)$ & $-1(60)$ & $0(0.8)$ & $0(0.8)$ \\
2 & $1(9)$ & $-1(60)$ & $0(0.8)$ & 2.675 \\
3 & $-1(7)$ & $1(80)$ & $0(0.8)$ & 2.777 \\
4 & $1(9)$ & $1(80)$ & $-1(0.6)$ & 2.726 \\
5 & $-1(7)$ & $0(70)$ & $-1(0.6)$ & 3.675 \\
6 & $1(9)$ & $0(70)$ & $1(1.0)$ & 2.905 \\
7 & $-1(7)$ & $0(70)$ & $1(1.0)$ & 3.030 \\
8 & $1(9)$ & $0(70)$ & $-1(0.6)$ & 2.371 \\
9 & $0(8)$ & $-1(60)$ & $-1(0.6)$ & 2.980 \\
10 & $0(8)$ & $1(80)$ & $1(1.0)$ & 2.827 \\
11 & $0(8)$ & $-1(60)$ & $1(1.0)$ & 3.056 \\
12 & $0(8)$ & $1(80)$ & $0(0.8)$ & 3.234 \\
13 & $0(8)$ & $0(70)$ & $0(0.8)$ & 3.208 \\
14 & $0(8)$ & $0(70)$ & $0(0.8)$ & 3.259 \\
15 & $0(8)$ & $0(70)$ & $0(0.8)$ & 3.234 \\
16 & $0(8)$ & $0(70)$ & $0(0.8)$ & 3.183 \\
17 & $0(8)$ & $0(70)$ &
\end{tabular}

TABLE 3: Analysis of variance of regression model.

\begin{tabular}{|c|c|c|c|c|c|c|}
\hline Parameter & Sum of squares & Df & Mean square & Standard error & $F$ value & $P$ value \\
\hline Intercept & - & 1 & - & 0.021 & - & - \\
\hline$X_{1}$ & 0.12 & 1 & 0.12 & 0.017 & 52.82 & $0.0002^{* *}$ \\
\hline$X_{2}$ & 0.30 & 1 & 0.30 & 0.017 & 136.66 & $<0.0001^{* *}$ \\
\hline$X_{3}$ & 0.077 & 1 & 0.077 & 0.017 & 35.19 & $0.0006^{* *}$ \\
\hline$X_{1} X_{2}$ & 0.093 & 1 & 0.093 & 0.023 & 42.25 & $0.0003^{* *}$ \\
\hline$X_{1} X_{3}$ & 0.010 & 1 & 0.010 & 0.023 & 4.74 & 0.0659 \\
\hline$X_{2} X_{3}$ & 0.036 & 1 & 0.036 & 0.023 & 16.45 & $0.0048^{* *}$ \\
\hline$X_{1}{ }^{2}$ & 0.32 & 1 & 0.32 & 0.023 & 147.66 & $<0.0001^{* *}$ \\
\hline$X_{2}^{2}$ & 0.58 & 1 & 0.58 & 0.023 & 266.10 & $<0.0001^{* *}$ \\
\hline$X_{3}{ }^{2}$ & $7.668 E-003$ & 1 & $7.668 E-003$ & 0.023 & 3.49 & 0.1038 \\
\hline Model & 1.62 & 9 & 0.18 & - & 81.77 & $<0.0001^{* *}$ \\
\hline Residual & 0.015 & 7 & $2.195 E-003$ & - & & \\
\hline Lack of fit & 0.012 & 3 & $4.001 E-003$ & - & 4.76 & 0.0829 \\
\hline Pure error & $3.361 E-003$ & 4 & $8.403 E-004$ & & & \\
\hline Cor total & 1.63 & 16 & & & & \\
\hline
\end{tabular}

endothermic peak. However, the major endothermic peak temperature of Se-SFPSIB $\left(176.12^{\circ} \mathrm{C}\right)$ was significantly lower than that of SFPSI $\left(180.50^{\circ} \mathrm{C}\right)$.

This phenomenon could be explained by chemical bonds and molecular orbital theory $[10,11]$. The studies confirmed that the $6^{\prime}-\mathrm{OH}$ in polysaccharide could be substituted by $\mathrm{HSeO}_{3}{ }^{-}$in selenylation, as shown in Figure $6[12,13]$.

When $\mathrm{HSeO}_{3}{ }^{-}$was introduced into SFPSIB and substituted $6^{\prime}-\mathrm{OH}, \mathrm{p}$ orbital of oxygen and $\mathrm{Se}=\mathrm{O}$ bond formed the $\mathrm{p}-\pi$ conjugated system in which the electron cloud of $\mathrm{C}-\mathrm{O}$ transferred to $\mathrm{Se}=\mathrm{O}$. This caused $\mathrm{C}-\mathrm{O}$ bond energy in Se-SFPSIB to be lower than that of SFPSIB, and C$\mathrm{O}$ bond in Se-SFPSIB could be broken easily. Therefore, the lower $\mathrm{C}-\mathrm{O}$ bond energy in Se-SFPSIB caused $\mathrm{HSeO}_{3}{ }^{-}$ group to be easily removed from Se-SFPSIB in the lower temperature. Further, the removal of $\mathrm{HSeO}_{3}{ }^{-}$accelerated SeSFPSIB decomposition. This confirmed that stability of SeSFPSIB was lower than that of SFPSIB. 
Size distribution by intensity

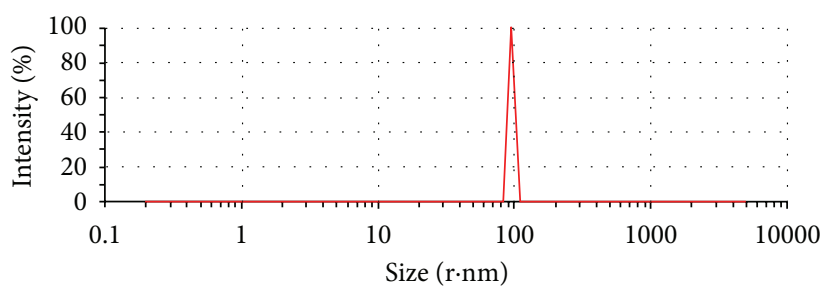

(a) $0.2 \mathrm{mg} / \mathrm{mL}$ Se-SFPSIB $(95.07 \mathrm{~nm})$
Size distribution by intensity

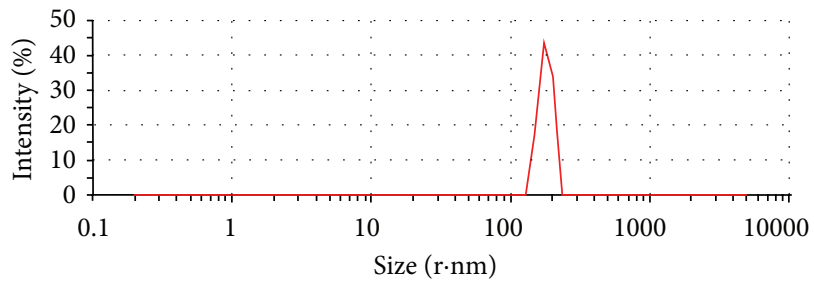

(b) $0.2 \mathrm{mg} / \mathrm{mL}$ SFPSIB $(177.40 \mathrm{~nm})$

FIGURE 3: Particle size distribution curves recorded for Se-SFPSIB and SFPSIB.

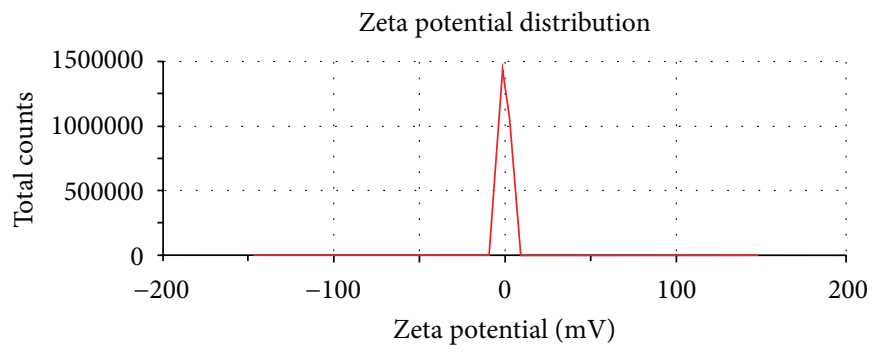

(a) $0.2 \mathrm{mg} / \mathrm{mL}$ Se-SFPSIB $(-0.194 \mathrm{mV})$

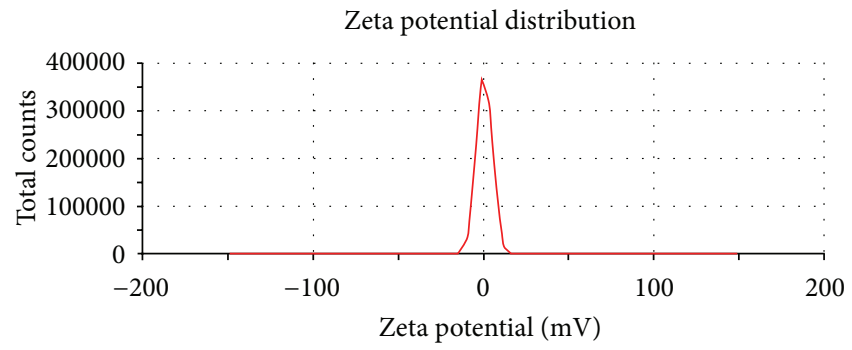

(b) $0.2 \mathrm{mg} / \mathrm{mL}$ SFPSIB $(0.489 \mathrm{mV})$

FIGURE 4: Zeta potential distribution curves recorded for Se-SFPSIB and SFPSIB.

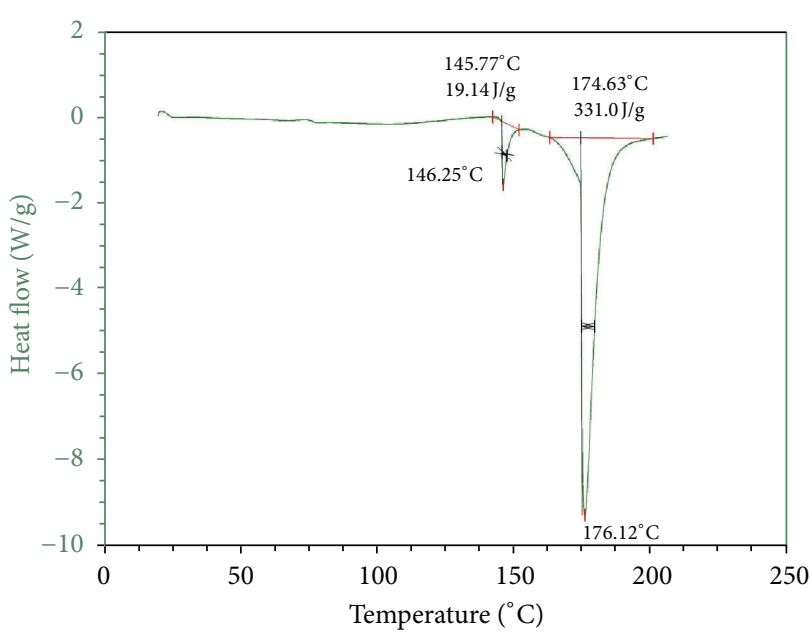

(a) Se-SFPSIB

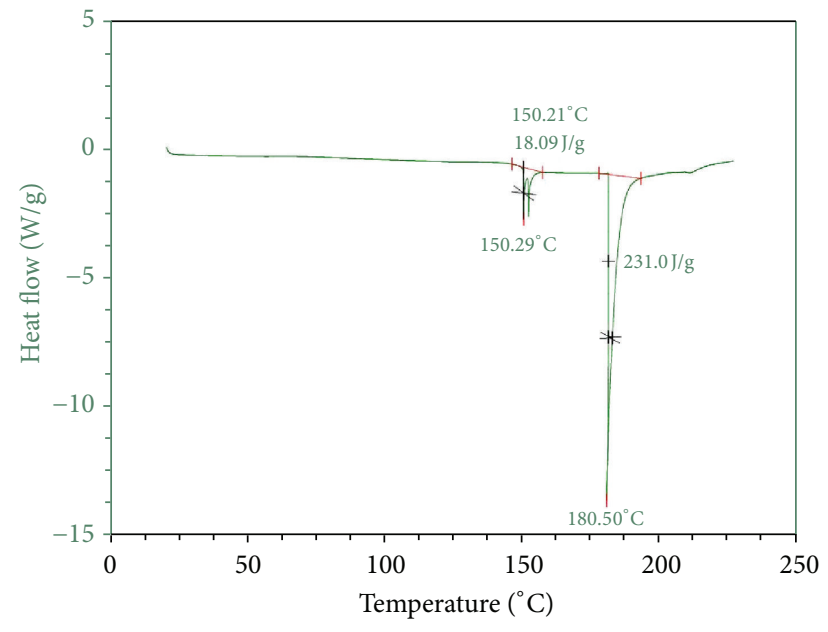

(b) SFPSIB

FIGURE 5: DSC curves recorded for (a) Se-SFPSIB and (b) SFPSIB.

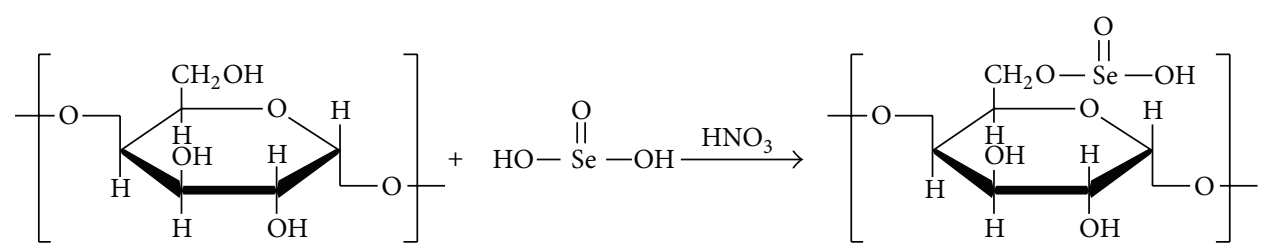

FIgURE 6: Selenylation mechanism of seleno-polysaccharide. 


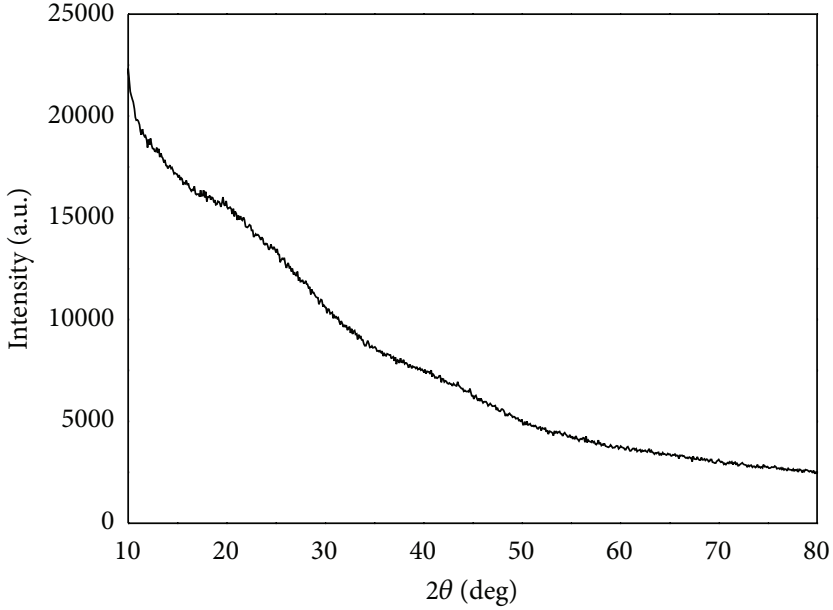

(a) Se-SFPSIB

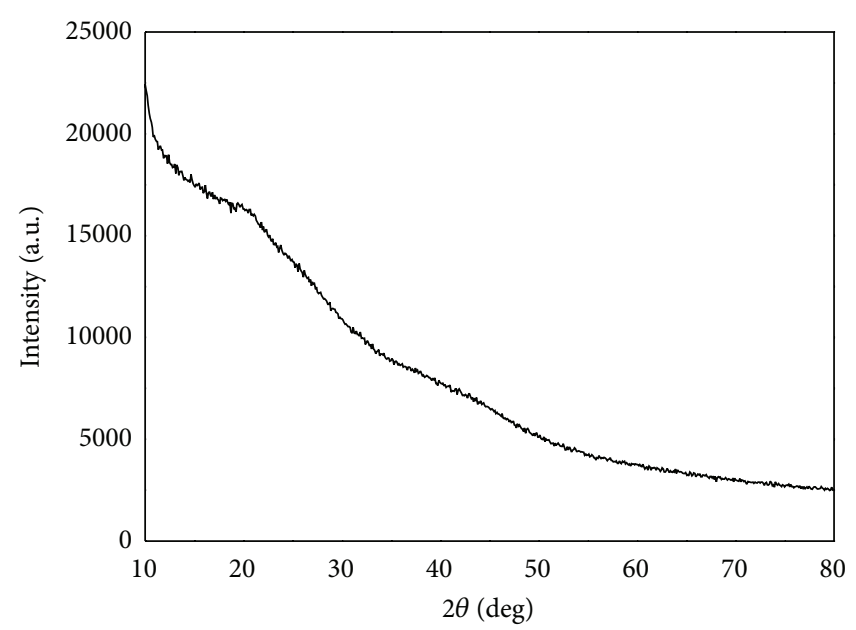

(b) SFPSIB

FIGURE 7: X-ray diffraction curves recorded for (a) Se-SFPSIB and (b) SFPSIB.
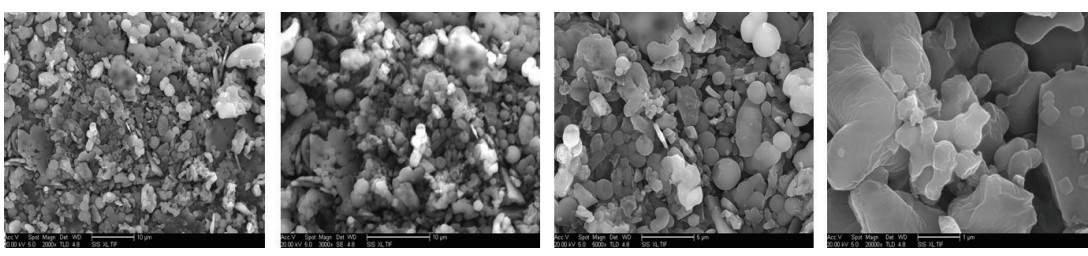

(a) Se-SFPSIB
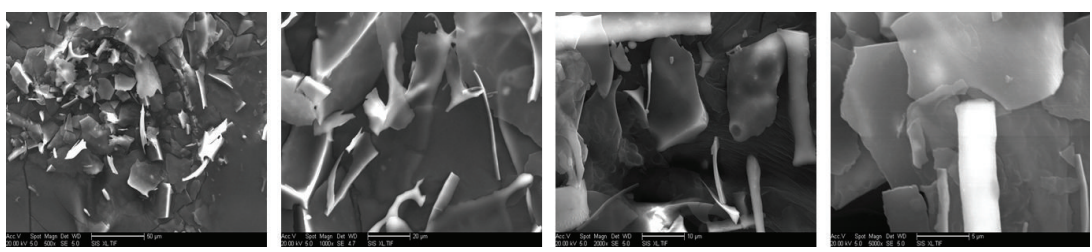

(b) SFPSIB

FIGURE 8: Scanning electron micrographs of Se-SFPSIB and SFPSIB.

3.6.3. X-Ray Diffraction Analysis. X-ray diffraction curves showed that Se-SFPSIB and SFPSIB were amorphous (Figure 7). This indicated that Se introduction had little effect on amorphous configuration of polysaccharide. This also explained that the regularity of polysaccharide molecules was poor and the configuration of polysaccharide was complex.

3.6.4. Shape in SEM. It could be seen from Figure 8 that the shape of Se-SFPSIB was spherical and cylindrical, but the shape of SFPSIB presented long strip and rod. The figures demonstrated that the three-dimensional image of SeSFPSIB was different from SFPSIB. This suggested that Se introduction could change polysaccharide morphology.

3.7. Antioxidant Activity Assay. One of the major reasons for tumorigenesis is lipid peroxidation in which oxygen free radicals, MDA, and other peroxides are produced to damage body.
As one of the key enzymes in antioxidant system, CAT could promote $\mathrm{H}_{2} \mathrm{O}_{2}$ decomposition and reduce $\mathrm{H}_{2} \mathrm{O}_{2}$ damage to cells $[14,15]$. It could be seen from Figure 9(a) that Se-SFPSIB could significantly improve the CAT activity in blood, heart, and liver $(P<0.01, P<0.05$, compared with negative group). Meanwhile, in comparison with the negative control, low Se-SFPSIB significantly improved CAT activity in blood, and mid-Se-SFPSIB group significantly improved CAT activity in liver. In addition, there were significant differences between Se-SFPSIB groups and SFPSIB group in heart $(P<0.01, P<0.05)$.

MDA is a main product in lipid peroxidation. It reflects the degree of the body damage [16-18]. According to Figure 9(b), Se-SFPSIB mainly reduced MDA in heart and liver. Compared with negative group, Se-SFPSIB significantly reduced MDA in liver $(P<0.01)$, and med-Se-SFPSIB and high-Se-SFPSIB groups significantly reduced the MDA in heart $(P<0.01, P<0.05)$. Besides, mid-Se-SFPSIB group decreased more MDA than SFPSIB in liver $(P<0.05)$. 


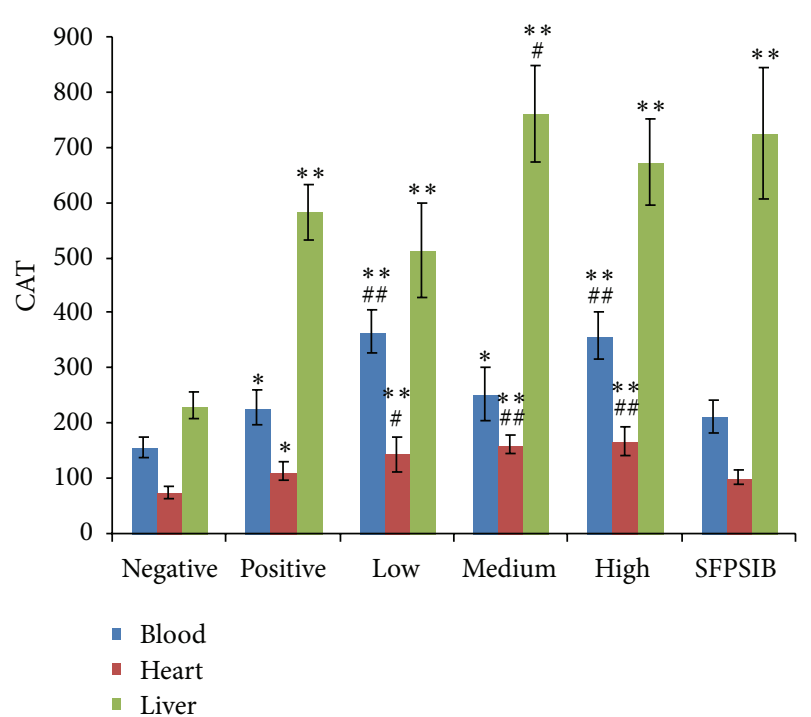

(a)

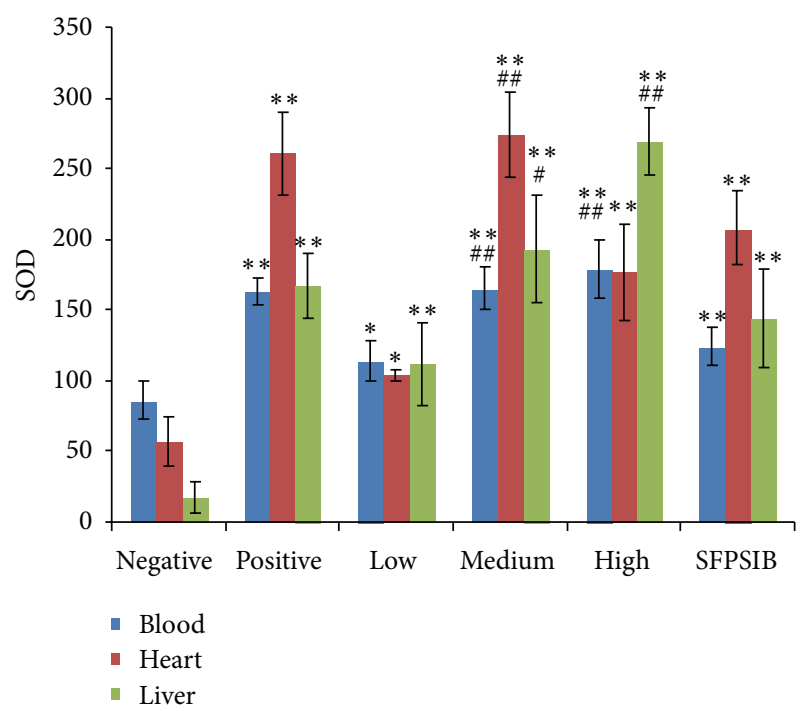

(c)

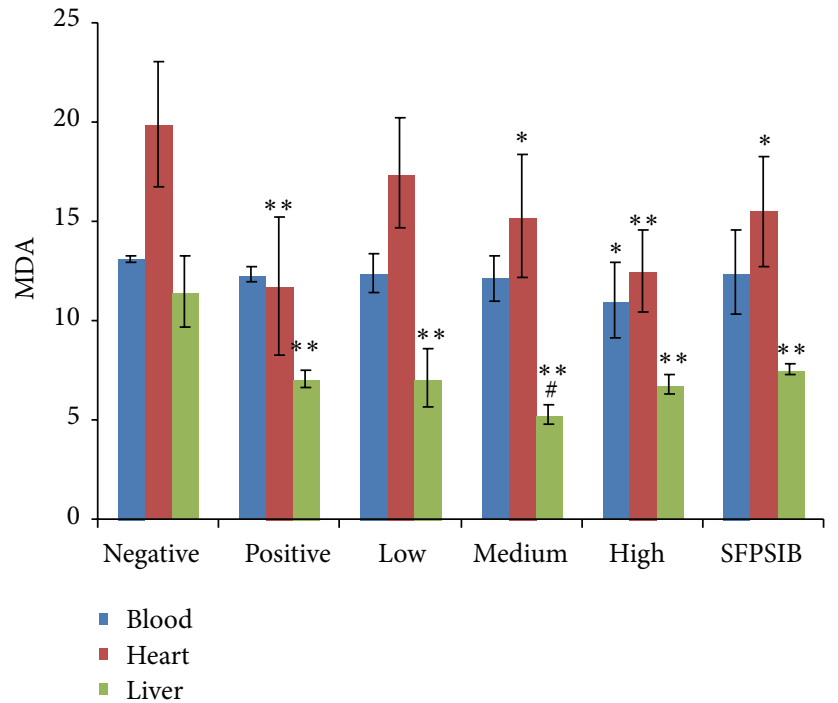

(b)

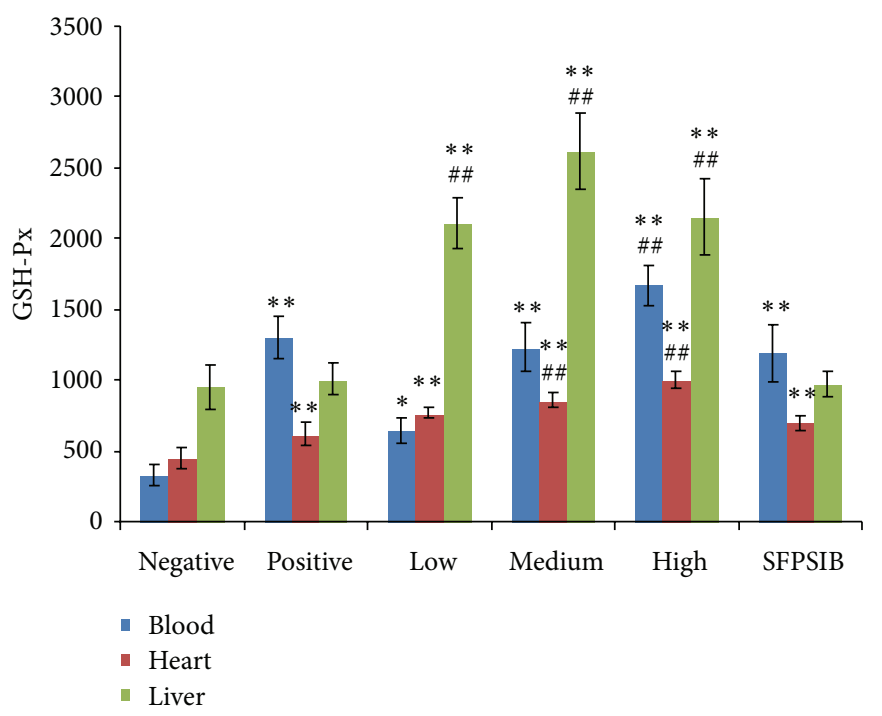

(d)

FIGURE 9: Effect of Se-SFPSIB on antioxidant system of mice bearing tumor $S_{180}$ in blood, heart, and liver. Compared with negative group, ${ }^{*} P<0.05,{ }^{* *} P<0.01$; compared with SFPSIB group, ${ }^{\#} P<0.05,{ }^{\# \#} P<0.01$. (a) Effect of Se-SFPSIB on CAT in blood (U/gHb), heart, and liver (U/gport); (b) effect of Se-SFPSIB on MDA in blood ( $\mathrm{nmol} / \mathrm{mL})$, heart, and liver (nmol/mgport); (c) effect of Se-SFPSIB on SOD in blood (U/mL), heart, and liver (U/mgport); (d) effect of Se-SFPSIB on GSH-Px in blood (U/mL), heart, and liver (U/gport).

SOD is an important active enzyme to scavenge oxygen free radical, prevent cells from attacking, and repair damaged cells [19-21]. As shown in Figure 9(c), there were significant differences between Se-SFPSIB groups and negative group $(P<0.01, P<0.05)$. Meanwhile, mid-Se-SFPSIB significantly increased SOD compared with SFPSIB $(P<0.01)$. The result demonstrated that SFPSIB could enhance more SOD activity than SFPSIB.

$\mathrm{Se}$ is well known as an essential trace element and an essential cofactor for GSH-Px, which is involved in scavenging free radicals and maintaining the redox balance [22-24]. Figure 9(d) showed that Se-SFPSIB significantly increased the GSH-Px activity in a dose-dependent manner (compared with the negative group, $P<0.01$ ). Further, compared with SFPSIB group, Se-SFPSIB groups extremely significantly enhance GSH-Px activity in liver $(P<0.01)$. Especially, high-Se-SFPSIB group significantly enhances GSH-Px activity more than SFPSIB group in heart $(P<0.01)$.

In short, Se-SFPSIB could enhance CAT of mice bearing tumor $\mathrm{S}_{180}$ to decompose $\mathrm{H}_{2} \mathrm{O}_{2}$ and improve SOD to decrease MDA level. Meanwhile, GSH-Px activity was extremely significantly enhanced through Se supplements from SeSFPSIB. The antioxidant results confirmed that antitumor ability of Se-SFPSIB was achieved by enhancing the antioxidant system. 


\section{Conclusion}

In this paper, the selenylation conditions for Se-SFPSI were optimized by RSM. The confirmatory experimental optimum conditions were reaction time of $8 \mathrm{~h}$, reaction temperature of $71^{\circ} \mathrm{C}$, and the ratio of $\mathrm{Na}_{2} \mathrm{SeO}_{3}$ to SFPSI of $1.0 \mathrm{~g} / \mathrm{g}$. The actual experimental Se content of $(3.352 \pm 0.04) \mathrm{mg} / \mathrm{g}$ closely matched the predicted value.

Furthermore, particle size, zeta potential, the thermal stability, and shape of Se-SFPSIB were significantly different from those of SFPSIB. Besides decreasing MDA, Se-SFPSIB also could enhance CAT, SOD, and GSH-Px activity. It demonstrated that Se-SFPSIB obtained from selenylation could significantly enhance antioxidant system and selenylation was a feasible approach to seek high biological functional seleno-polysaccharide.

\section{Conflict of Interests}

The authors declare no conflict of interests.

\section{Acknowledgment}

This work was supported by National Natural Science Foundation, China (30672595).

\section{References}

[1] J. Duan, V. L. Chen, Q. Dong, K. Ding, and J. Fang, "Chemical structure and immunoinhibitory activity of a pectic polysaccharide containing glucuronic acid from the leaves of Diospyros kaki," International Journal of Biological Macromolecules, vol. 46, no. 5, pp. 465-470, 2010.

[2] X. Chen, W. Nie, S. Fan et al., "A polysaccharide from Sargassum fusiforme protects against immunosuppression in cyclophosphamide-treated mice," Carbohydrate Polymers, vol. 90, no. 2, pp. 1114-1119, 2012.

[3] X. Chen, W. Nie, G. Yu et al., "Antitumor and immunomodulatory activity of polysaccharides from Sargassum fusiforme," Food and Chemical Toxicology, vol. 50, no. 3-4, pp. 695-700, 2012.

[4] J. Zhou, N. Hu, Y. L. Wu, Y. J. Pan, and C. R. Sun, "Preliminary studies on the chemical characterization and antioxidant properties of acidic polysaccharides from Sargassum fusiforme," Journal of Zhejiang University, vol. 9, no. 9, pp. 721-727, 2008.

[5] O. Micke, L. Schomburg, J. Buentzel, K. Kisters, and R. Muecke, "Selenium in oncology: from chemistry to clinics," Molecules, vol. 14, no. 10, pp. 3975-3988, 2009.

[6] C. D. Davis and R. Irons, "Are selenoproteins important for the cancer protective effects of selenium?" Current Nutrient Food Science, vol. 1, pp. 201-214, 2005.

[7] L. Schomburg and J. Koehrle, "Selenium: benefits and risks," MMW-Fortschritte der Medizin, vol. 149, no. 8, pp. 34-36, 2007.

[8] D. Shang, Y. Li, C. Wang, X. Wang, Z. Yu, and X. Fu, "A novel polysaccharide from Se-enriched Ganoderma lucidum induces apoptosis of human breast cancer cells," Oncology Reports, vol. 25, no. 1, pp. 267-272, 2011.

[9] J. W. Li, L. F. Zhang, and Y. F. Liu, "Optimization of extraction of natural pigment from purple sweet potato by response surface methodology and its stability," Journal of Chemistry, vol. 2013, Article ID 590512, 5 pages, 2013.
[10] Y. B. Ji, F. Dong, and L. Lang, "Optimization of synthesis, characterization and cytotoxic activity of seleno-Capparis spionosa L. polysaccharide," International Journal of Molecular Sciences, vol. 13, no. 12, pp. 17275-17289, 2012.

[11] Z. G. She, G. P. Hu, Z. Y. Guo, Y. C. Lin, and M. L. Lin, "Study on the thermal decomposition of the sulphated polysaccharide Hal-A from Haliotis diverisicolor reeve," Chinese Journal of Organic Chemistry, vol. 23, no. 10, pp. 1149-1151, 2003.

[12] J. Zhang, Z. W. Liu, F. X. Wang et al., "Synthesis and characterization of seleno-Lilium davidii var. unicolor salisb polysaccharides," Polymer Bulletin, vol. 10, pp. 48-52, 2009.

[13] J. Zhang, F. X. Wang, Z. W. Liu et al., "Synthesis and characterisation of seleno-Cynomorium songaricum Rupr. polysaccharide," Natural Product Research, vol. 23, no. 17, pp. 1641-1651, 2009.

[14] J. Q. Shi, Z. X. Wu, and L. R. Song, "Physiological and molecular responses to calcium supplementation in Microcystis aeruginosa (Cyanobacteria)," New Zealand Journal of Marine and Freshwater Research, vol. 47, no. 1, pp. 51-61, 2013.

[15] L. Liu, J. Jia, G. Zeng et al., "Studies on immunoregulatory and anti-tumor activities of a polysaccharide from Salvia miltiorrhiza Bunge," Carbohydrate Polymers, vol. 92, no. 1, pp. 479-483, 2013.

[16] L. Zhang, C. Liu, D. Li et al., "Antioxidant activity of an exopolysaccharide isolated from Lactobacillus plantarum C88," International Journal of Biological Macromolecules, vol. 54, pp. 270-275, 2013.

[17] N. M. Ali, H. M. Yusof, K. Long et al., "Antioxidant and hepatoprotective effect of aqueous extract of germinated and fermented Mung Bean on ethanol-mediated liver damage," BioMed Research International, vol. 2013, Article ID 693613, 9 pages, 2013.

[18] W. B. Wang, Y. C. Wang, X. Shu, and Q. Zhang, "Physiological responses of soil crust-forming cyanobacteria to diurnal temperature variation," Journal of Basic Microbiology, vol. 53, no. 1, pp. 72-80, 2013.

[19] Y. K. Hong, W. J. Liu, T. Li, and S. Y. She, "Optimization of extraction of Eucommia ulmoides polysaccharides by response surface methodology," Carbohydrate Polymers, vol. 92, no. 2, pp. 1761-1766, 2013.

[20] F. W. Yan, F. Fang, H. M. Jin et al., "Influence of tartary buckwheat extracts supplementation on oxidative stress induced by acute exhaustive exercise in eats," International Journal of Pharmacology, vol. 8, no. 8, pp. 695-700, 2012.

[21] C. S. He, H. Y. Yue, J. Xu et al., "Protective effects of capillary artemisia polysaccharide on oxidative injury to the liver in rats with obstructive jaundice," Experimental and Therapeutic Medicine, vol. 4, no. 4, pp. 645-648, 2012.

[22] Y. L. Gao, C. M. Li, J. G. Yin et al., "Fucoidan, a sulfated polysaccharide from brown algae, improves cognitive impairment induced by infusion of $\mathrm{A} \beta$ peptide in rats," Environmental Toxicology and Pharmacology, vol. 33, no. 2, pp. 304-311, 2012.

[23] C. J. Li, X. L. Wu, X. J. Lou, Y. Wu, A. Li, and H. Wang, "Protective effects of crude polysaccharide from gynostemma pentaphyllum on swimming exercise-induced oxidative stress in rat," Journal of Animal and Veterinary Advances, vol. 11, no. 10, pp. 1627-1632, 2012.

[24] Z. Sui, L. Li, B. Liu et al., "Optimum conditions for radix rehmanniae polysaccharides by RSM and its antioxidant and immunity activity in UVB mice," Carbohydrate Polymers, vol. 92, no. 1, pp. 283-288, 2013. 

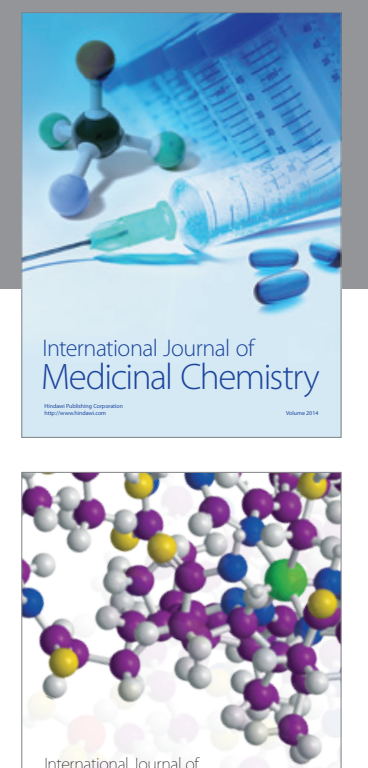

\section{Carbohydrate} Chemistry

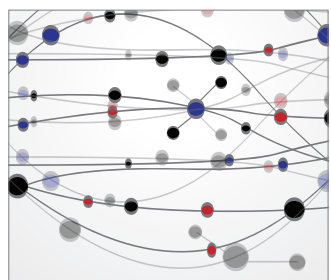

The Scientific World Journal
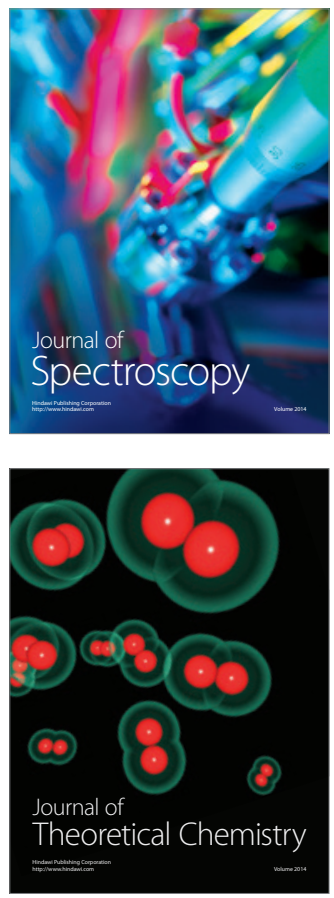
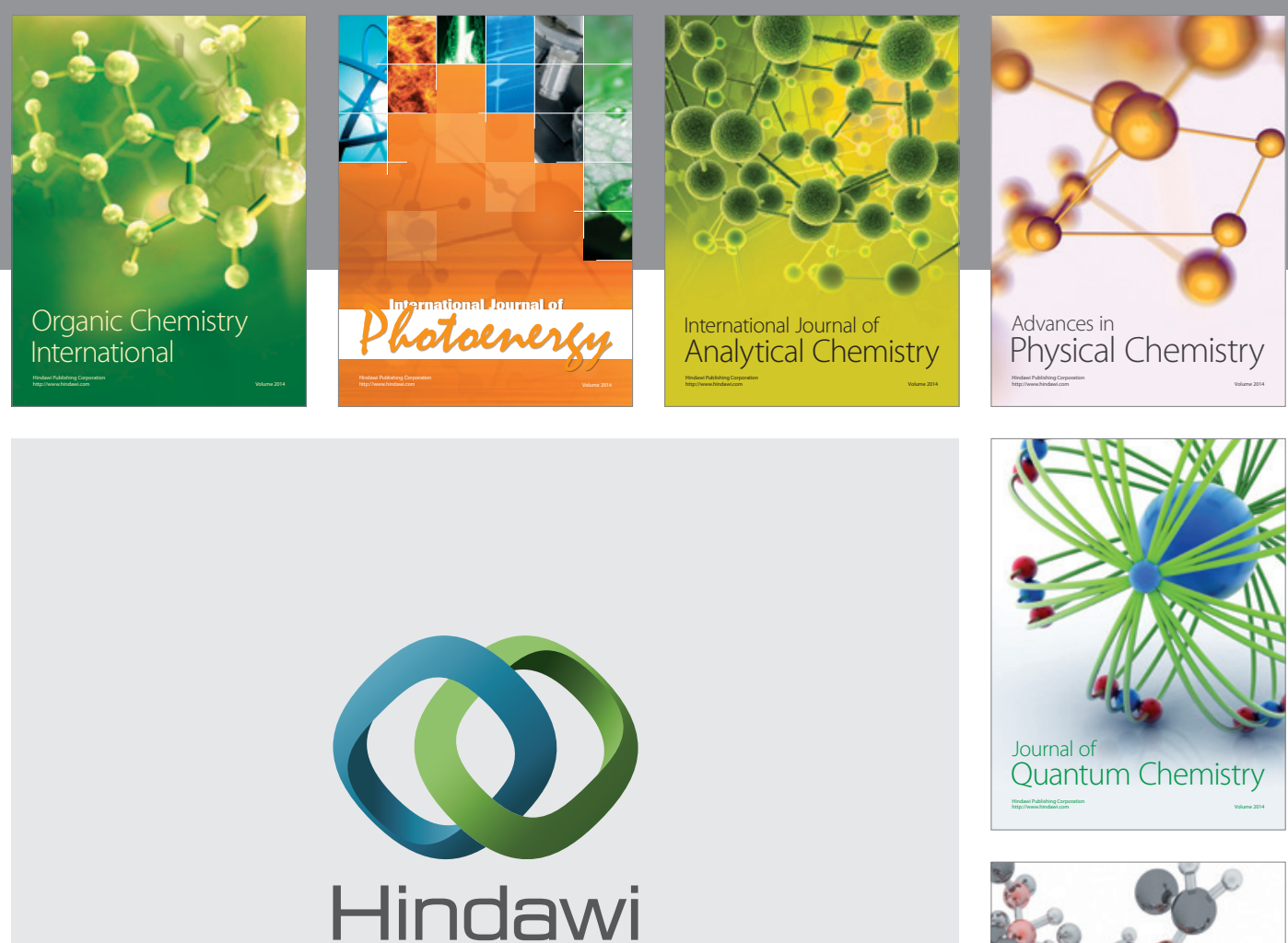

Submit your manuscripts at

http://www.hindawi.com

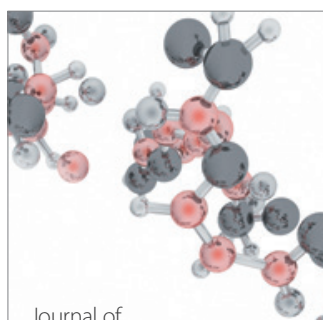

Analytical Methods

in Chemistry

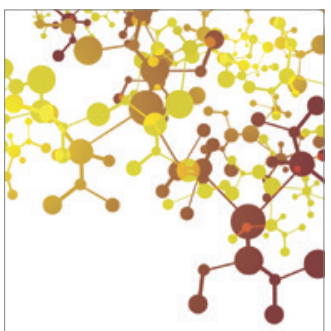

Journal of

Applied Chemistry

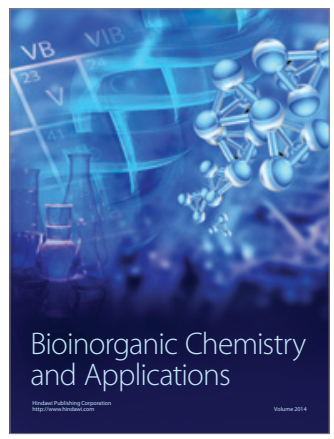

Inorganic Chemistry
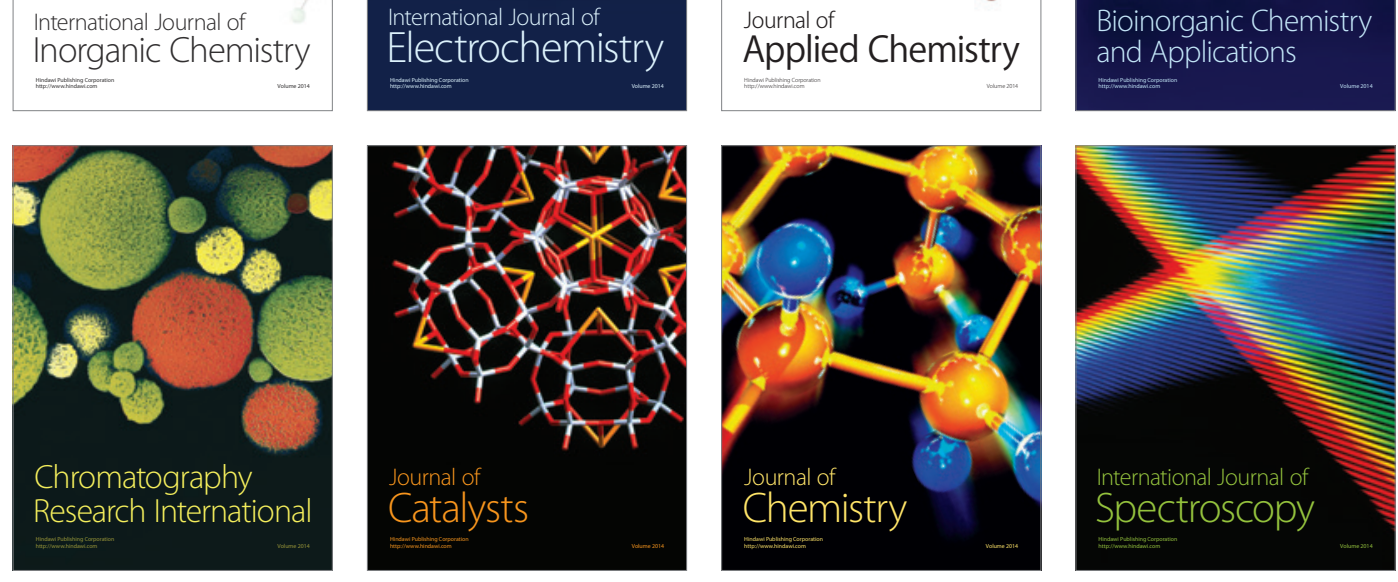